\title{
The influence of intraannular templates on the liquid crystallinity of shape-persistent macrocycles
}

\author{
Joscha Vollmeyer ${ }^{1}$, Ute Baumeister ${ }^{*}$ and Sigurd Höger ${ }^{* 1}$
}

\section{Full Research Paper}

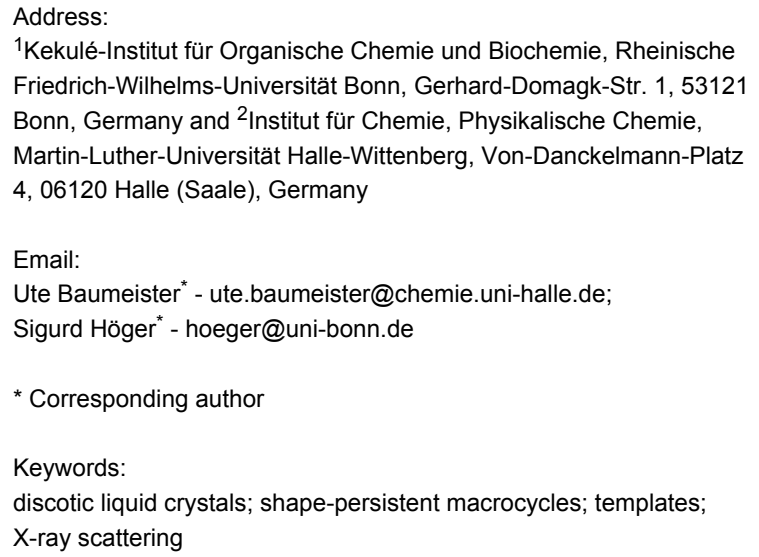

${ }^{1}$ Kekulé-Institut für Organische Chemie und Biochemie, Rheinische Friedrich-Wilhelms-Universität Bonn, Gerhard-Domagk-Str. 1, 53121 Bonn, Germany and ${ }^{2}$ Institut für Chemie, Physikalische Chemie, Martin-Luther-Universität Halle-Wittenberg, Von-Danckelmann-Platz 4, 06120 Halle (Saale), Germany

Email:

Ute Baumeister ${ }^{*}$ - ute.baumeister@chemie.uni-halle.de;

Sigurd Höger* - hoeger@uni-bonn.de

* Corresponding author

Keywords:

discotic liquid crystals; shape-persistent macrocycles; templates;

X-ray scattering

Beilstein J. Org. Chem. 2014, 10, 910-920.

doi:10.3762/bjoc. 10.89

Received: 16 January 2014

Accepted: 27 March 2014

Published: 23 April 2014

This article is part of the Thematic Series "Chemical Templates".

Associate Editor: S. C. Zimmerman

(C) 2014 Vollmeyer et al; licensee Beilstein-Institut. License and terms: see end of document.

\begin{abstract}
A series of shape-persistent phenylene-ethynylene-naphthylene-butadiynylene macrocycles with different extraannular alkyl groups and intraannular bridges is synthesized by oxidative Glaser-coupling of the appropriate precursors. The intraannular bridges serve in this case as templates that reduce the oligomerization even when the reaction is not performed under pseudo high-dilution conditions. The extraannular as well as the intraannular substituents have a strong influence on the thermal behavior of the compounds. With branched alkyl chains at the periphery, the macrocycles exhibit liquid crystalline (lc) phases when the interior is empty or when the length of the alkyl bridge is just right to cross the ring. With a longer alkyl or an oligoethylene oxide bridge no lc phase is observed, most probably because the mesogene is no longer planar.
\end{abstract}

\section{Introduction}

The supramolecular chemistry of shape-persistent macrocycles has enormously expanded during the past several years [1-6]. It covers the non-covalent interaction between the compound molecules and also the interaction between the macrocycles and appropriate partners. For example, the 2D organization of shape-persistent macrocycles at suitable surfaces leads to longrange ordered patterns with nanoscale lattice parameters and, moreover, even to the epitaxial absorption of appropriate guest molecules on this macrocycle template [7-10]. In solution, shape-persistent macrocycles aggregate into defined dimers or up to $\mu \mathrm{m}$ long fibers that can form gels (in solution) or can be casted to yield efficient sensor materials [11-23]. Amphiphilic macrocycles in aqueous solution have been shown to be able to form vesicles [24,25]. In the bulk state, most of the macrocycles crystallize and some could be explored by single-crystal X-ray analysis [26-28]. Heating crystalline macrocycles above 
the melting point does not always lead immediately to an isotropic melt, but thermotropic mesophases are observed when the macrocycles have an appropriately substituted rim [29-35]. If the macrocycles pack on top of each other, hexagonal columnar or rectangular columnar phases can be observed in which the (empty) interior is able to accommodate small guest molecules [36-39]. In some cases, however, macrocycles with a filled interior seem to exhibit more stable mesophases compared to the compounds alike but with an empty interior [40]. Moreover, it has also been observed that even macrocycles with a flexible interior only, lacking the flexible rim, can form stable mesophases (macrocycles with an inverse structure) [41-43].

Recently, we presented a series of gel forming macrocycles that have an identical periphery but bear different intraannular substituents [11]. We were able to show that these substituents influence the thermal stability of the gel. As pointed out before, the ring interior can also have a dramatic effect on the mesophase stability of thermotropic liquid crystalline shapepersistent macrocycles [40,43-45]. However, more detailed studies on that issue are still scarcely found in the literature. Here, we designed and synthesized macrocycles 1-4 with flexible extraannular alkyl groups and a fixed intraannular chain that crosses the ring interior (Figure 1) and acts during the synthesis as a template. We studied the influence of the extra- and intraannular substituents on the molecule's ability to form liquid crystalline phases. The macrocycles are based on a phenylene-ethynylene-naphthylene-butadiynylene backbone. Naphthylene units at the four corners are expected to have a higher mesomorphic tendency compared with compounds

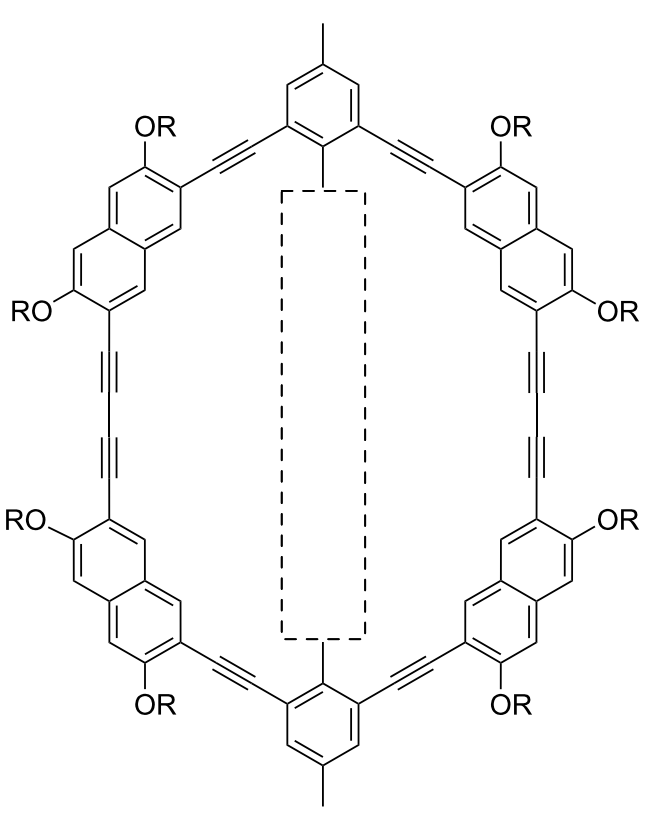

$$
\mathrm{R}=
$$<smiles>Cc1cc(C)cc(I)c1</smiles>

1d

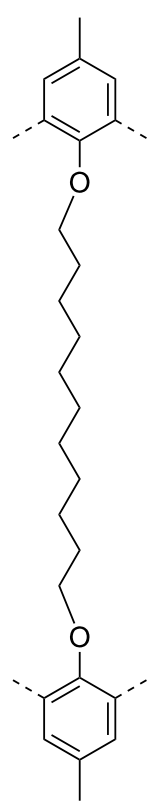

$1 \mathrm{a}$<smiles>Cc1cc(C)c(OCCCCCCCCCCCCCCOc2c(C)cc(C)cc2C)c(C)c1</smiles>

$1 b$<smiles>Cc1cc(C)c(OCCOCCOCCOCCOc2c(C)cc(C)cc2C)c(C)c1</smiles>

$1 c$

\begin{tabular}{|c|c|c|c|}
\hline$n-\mathrm{C}_{18} \mathrm{H}_{37}$ & 2d & $2 a$ & 2c \\
\hline$n-\mathrm{C}_{16} \mathrm{H}_{33}$ & & $3 a$ & \\
\hline$n-\mathrm{C}_{12} \mathrm{H}_{25}$ & & $4 a$ & \\
\hline
\end{tabular}


solely based on phenylene units [46]. Moreover, the naphthylene corners allow an efficient surrounding of the macrocycles with an alkyl fringe, according to the general design principle for discotic liquid crystals [47]. In addition to the macrocycles with intraannular bridges, we also synthesized and investigated a corresponding compound with an empty interior (1d).

\section{Results and Discussion}

\section{Synthesis}

\section{Template-based macrocycles}

The synthesis of the macrocycle $\mathbf{1}$ follows our often used strategy to dimerize appropriate rigid bisacetylenes oxidatively [48]. This coupling reaction can be performed statistically or template supported, where the latter is either non-covalently or covalently bound to the bisacetylenes $[45,49,50]$. The template does not necessarily only support the desired cyclization, it can also take over an active function in the final target structure. Covalently attached templates have the advantage over most of the supramolecular templates of being robust against solvent or temperature changes and will still be applicable at elevated temperatures. The bisacetylenes can be prepared independently and attached to the template just prior to the cyclization reaction or, and this is done here, the (template bound) oligoacetylene is prepared at the template [51].

Scheme 1 shows the general synthetic approach towards the macrocycles with an intraannular flexible bridge. The tetraiodide $\mathbf{5}$, which contains the two phenylene ring corners and the
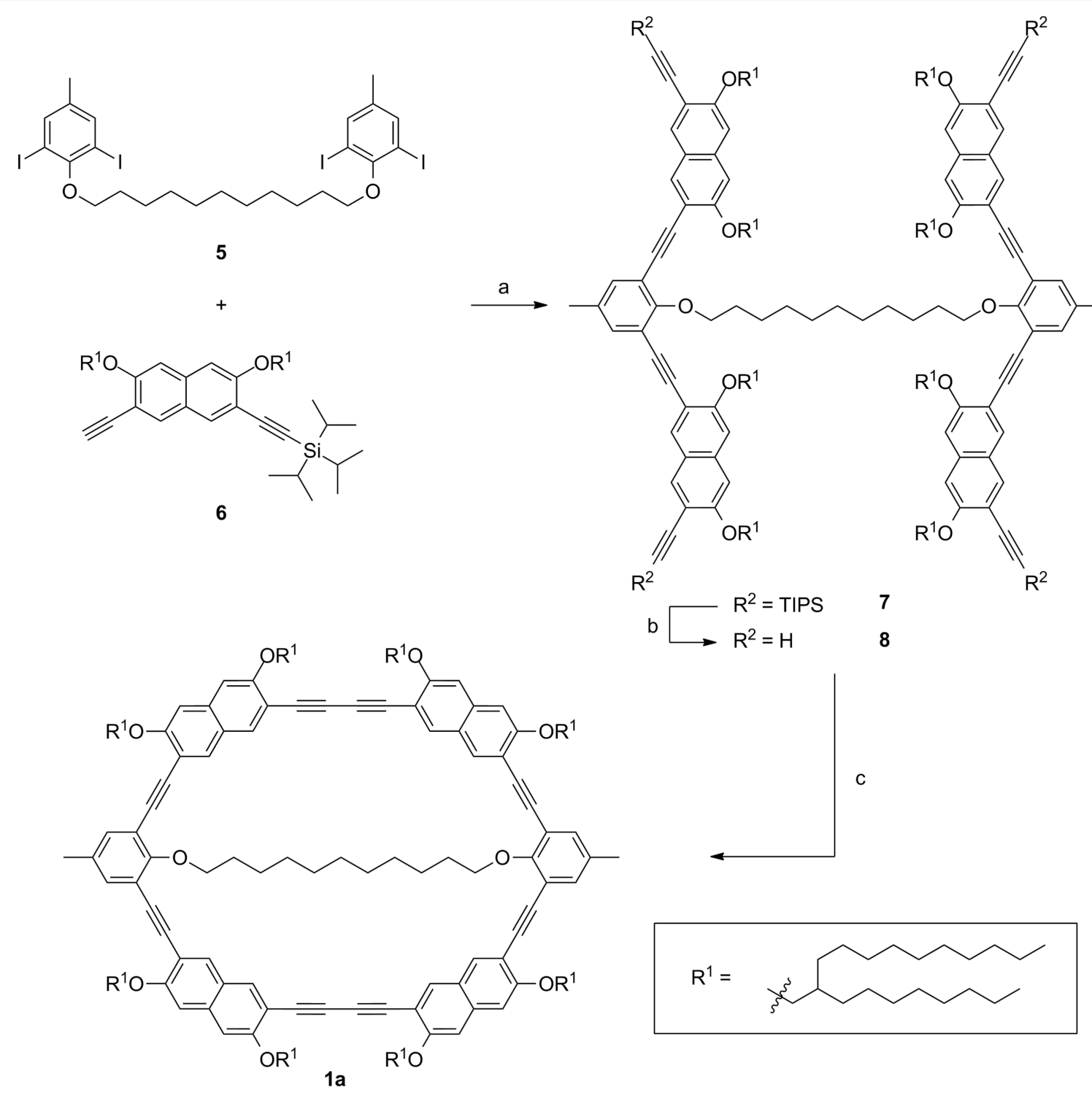

$1 \mathrm{a}$

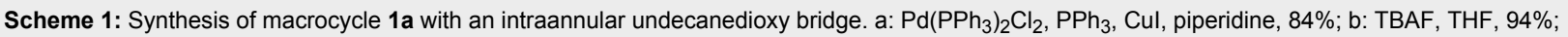
c: $\mathrm{Pd}\left(\mathrm{PPh}_{3}\right)_{2} \mathrm{Cl}_{2}$, Cul, 1,4-benzoquinone, piperidine, THF, $49 \%$. 
flexible alkyl template, as well as the naphthylene units $\mathbf{6}$ are synthesized independently (see Supporting Information File 1). Then $\mathbf{6}$ is attached to $\mathbf{5}$ in a fourfold Sonogashira-Hagihara reaction. To compensate the acetylene dimerization side reaction, the acetylene is added in $25 \%$ excess. Fluoride-induced removal of the silyl protecting groups yields the precursor 7 . With $\mathrm{Pd}\left(\mathrm{PPh}_{3}\right)_{2} \mathrm{Cl}_{2}$ and $\mathrm{CuI}$ as catalysts and 1,4-benzoquinone as oxidant, the precursor is finally intramolecular cyclized in THF/piperidine under high-dilution conditions by slowly adding (48 hours) a solution of the tetraacetylene to the reaction media.

Gel permeation chromatography (GPC) analysis of the crude product indicates that only few oligomeric byproducts are formed (Figure 2). With the aid of recycling GPC (recGPC) these impurities could be removed and $1 \mathrm{a}$ is obtained in $49 \%$ yield. Following this synthetic route we synthesized the macrocycles $1 \mathbf{a}-\mathbf{c}$ as well as the macrocycles $\mathbf{3 a}$ and $\mathbf{4 a}$ with different side chains (Figure 1, see Supporting Information File 1 for experimental details and reference [11] for the preparation of 2a-d).

\section{Statistical macrocycle synthesis}

Macrocycle 1d without intraannular substituents is obtained via statistical dimerization of the halfring $\mathbf{1 0}$ (Scheme 2). The half ring synthesis follows the above described approach and precursor $\mathbf{1 0}$ is cyclized under the same conditions as described

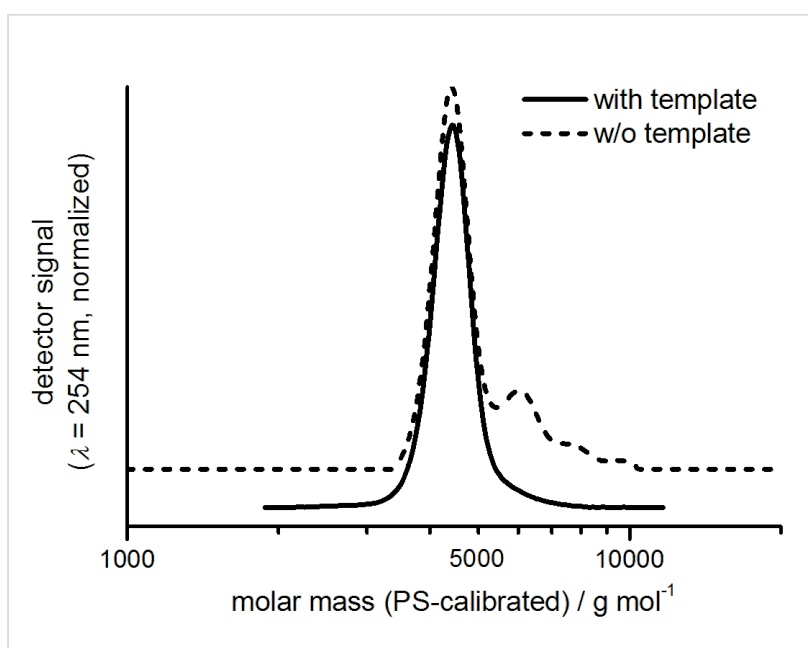

Figure 2: GPC elugrams of the crude product of the cyclization reaction of $\mathbf{1 a}(-)$ and $\mathbf{1 d}(---)$, respectively. For a better view the curves are vertically shifted.

for the template-mediated reaction. The GPC trace of the crude product shows significant amounts of oligomeric byproducts (Figure 2). Nevertheless, after purification by means of recGPC, macrocycle $1 \mathrm{~d}$ is obtained in a yield of $57 \%$.

The comparison of the GPC traces of the crude products of 1a and $\mathbf{1 d}$ shows that in the intramolecular reaction less oligomers

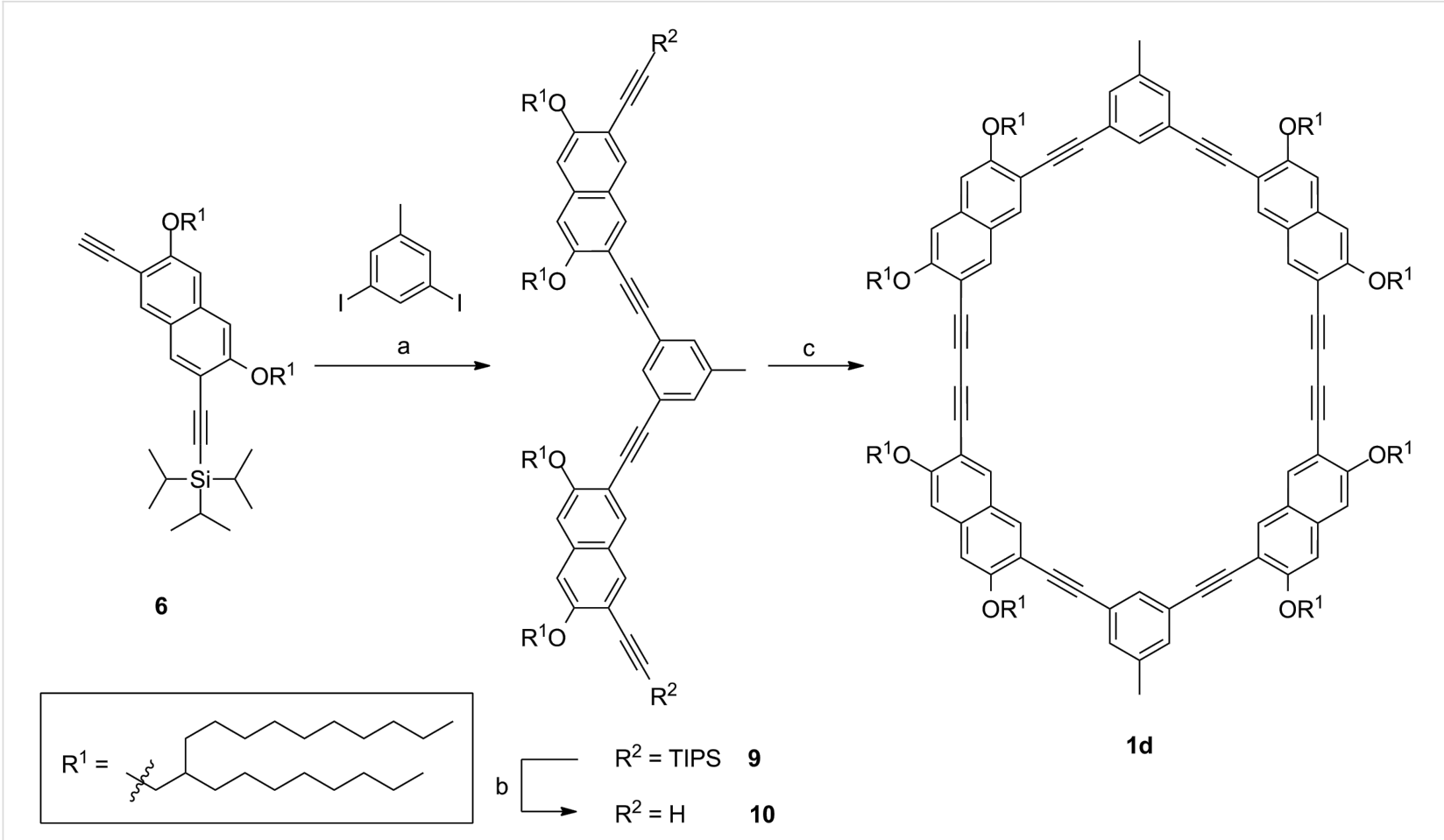

Scheme 2: Synthesis of the template free macrocycle 1d. a: $\mathrm{Pd}\left(\mathrm{PPh}_{3}\right)_{2} \mathrm{Cl}_{2}, \mathrm{PPh}_{3}$, Cul, piperidine, $98 \%$; b: TBAF, THF, quant.; c: $\mathrm{Pd}_{(}\left(\mathrm{PPh}_{3}\right)_{2} \mathrm{Cl}_{2}, \mathrm{Cul}$, 1,4-benzoquinone, piperidine, THF, $50{ }^{\circ} \mathrm{C}, 57 \%$. 
are formed than in the intermolecular reaction. However, the yields of the cyclization reactions do not differ significantly. That indicates that in the template-mediated cyclization side reactions cannot be completely suppressed. In the statistical half ring dimerization, the most important side reaction is the oligomerization of the half rings. Beside the desired dimers also trimers, tetramers, and other oligomers are formed, which can undergo further oligomerization reactions or may cyclize. These cyclic oligomers are still soluble and therefore they can be detected by GPC. In case of the template connected half rings, we assume that the oligomers formed through an intermolecular reaction cross-link, most likely form insoluble polymers, and are therefore not detected in the GPC analysis. The template has therefore two effects in the cyclization: (1) The terminal acetylenes are hold in proximity, thus, an intramolecular reaction is favored over an intermolecular reaction. (2) If an intermolecular coupling has occurred, the template leads to easily separable (insoluble) byproducts. However, the unexpected moderate yield in the template-directed synthesis suggests that the material may slowly decompose under the cyclization condition. Since other protocols (e.g., $\mathrm{CuCl} / \mathrm{CuCl}_{2}$ in pyridine) did not give reproducible results, we tested whether high-dilution conditions can be omitted. For this purpose, we performed the cyclization towards macrocycle 1c not under pseudo high-dilution conditions but by stirring a solution of the complete starting material of $\mathbf{1 c}$ at once in THF, piperidine, $\mathrm{Pd}\left(\mathrm{PPh}_{3}\right) \mathrm{Cl}_{2}$ and $\mathrm{CuI}$ as catalysts and 1,4-benzoquinone as oxidant for $3 \mathrm{~h}$ at $60{ }^{\circ} \mathrm{C}$ and obtained $1 \mathrm{c}$ in $56 \%$ yield (after purification, see Supporting Information File 1). This result additionally emphasizes the potential of template-mediated reactions, which not only can be more efficient in terms of reducing byproducts but also paves the way towards a fast coupling protocol.

\section{Phase behavior \\ Thermal properties}

By means of polarized optical microscopy (POM) and differential scanning calorimetry (DSC) we investigated the thermal properties of the macrocycles $\mathbf{1 - 4}$. The transition temperatures are shown in Figure 3 and listed in Table 1.

\section{(a)}
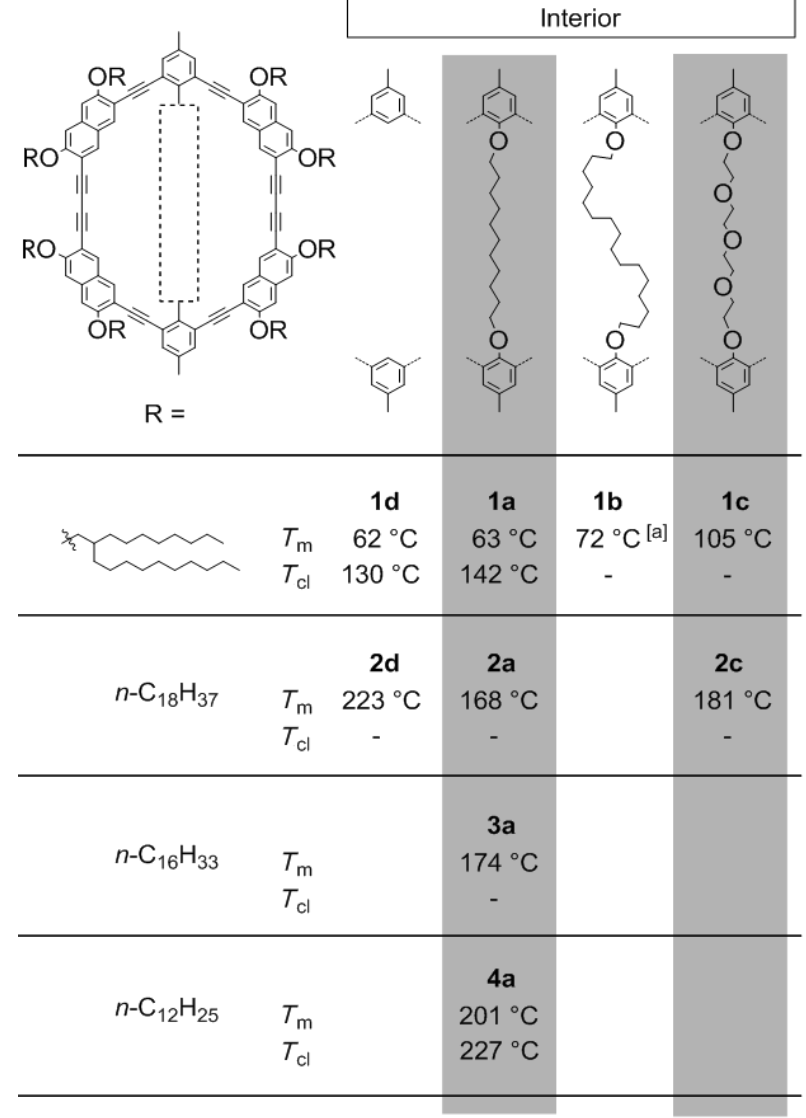

(b)
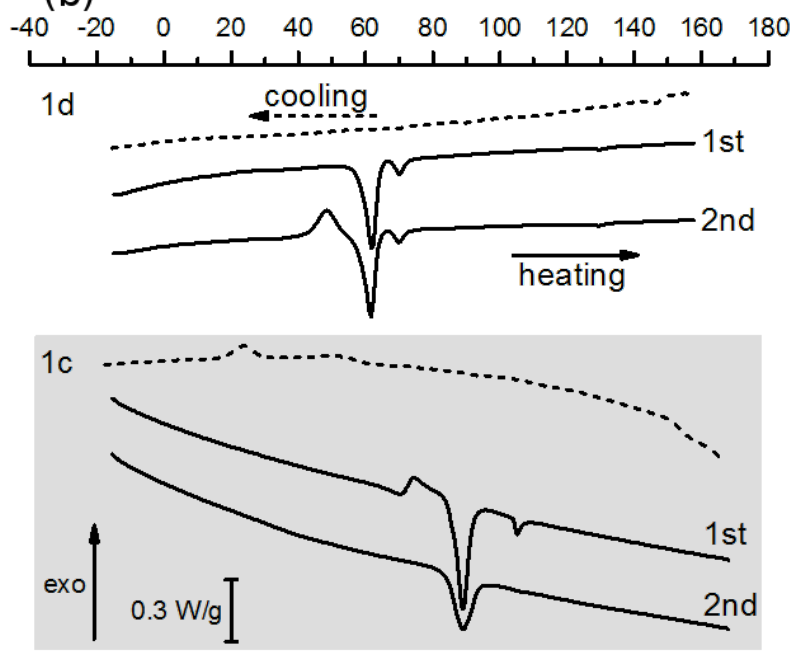

$1 \mathrm{~b}$

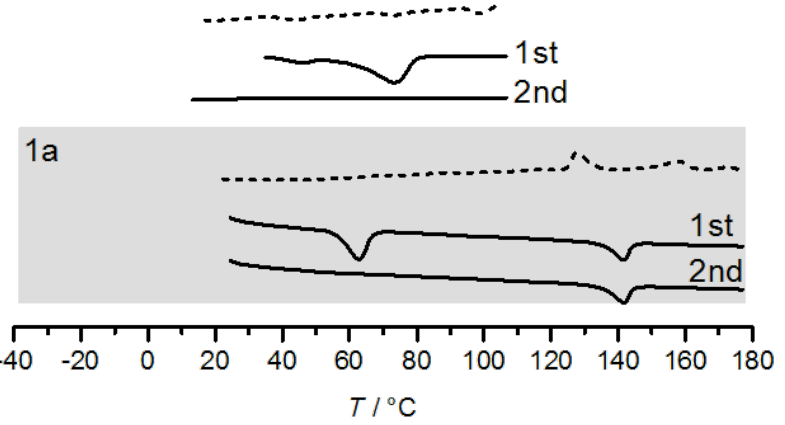

Figure 3: (a) Melting points $\left(T_{\mathrm{m}}\right)$ and clearing points $\left(T_{\mathrm{cl}}\right)$ of macrocycles with different interior. ${ }^{[a]}$ First heating. (b) DSC heat-flux curves of 1a-d $(10 \mathrm{~K} / \mathrm{min})$. 
Table 1: Phase transitions and corresponding enthalpies of the discussed macrocycles.

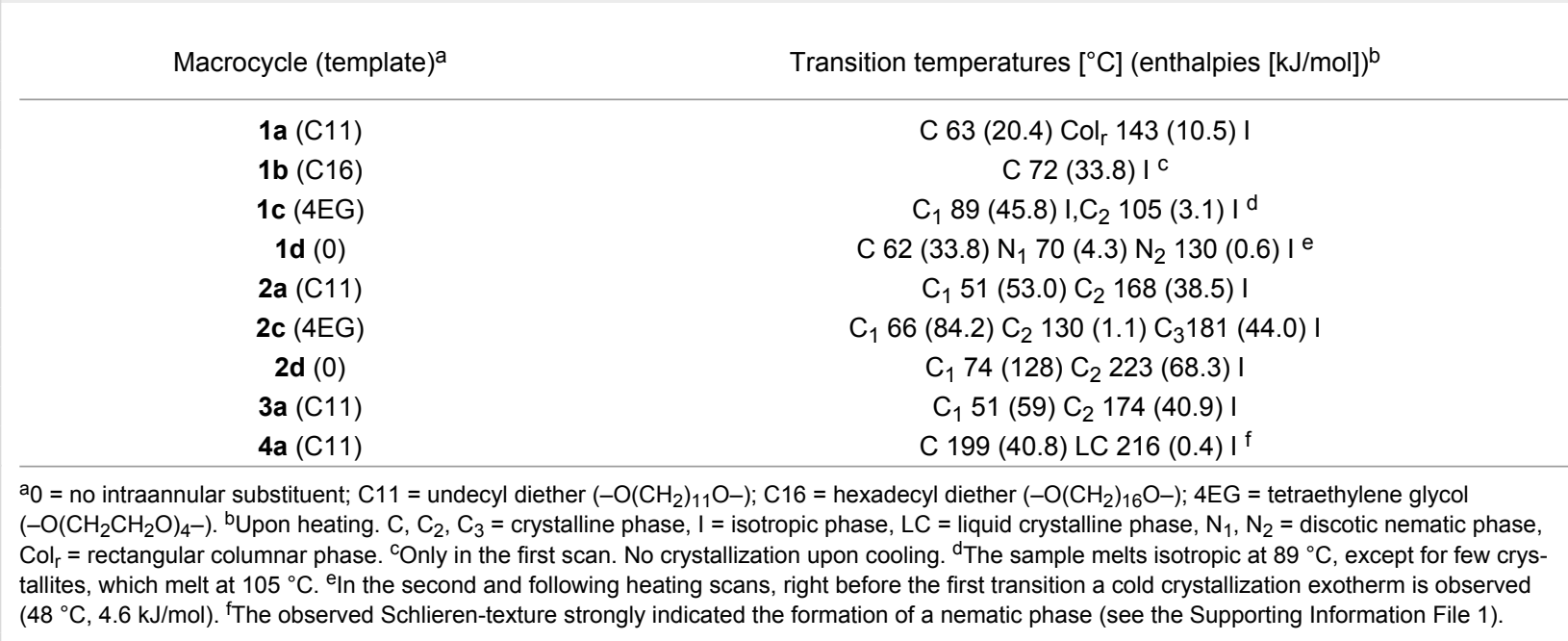

\section{Extraannular substitution}

It is well known that the periphery of discotic molecules generally dominates their thermal behavior. Shortening the side chains usually increases the melting point, whereas longer side chains or branched alkyl groups have the opposite effect $[47,52,53]$. However, when the side groups become too long or bulky, the compound melts isotropically and does not exhibit a mesophase [47]. By comparing the macrocycles 1a, 2a, 3a, and 4a, all with the same intraannular alkyl template the melting points decrease with increasing length of the extraannular alkyl chains. The lowest transition temperature is observed for $\mathbf{1 a}$, with branched side chains (Figure 3a), as it is also observed for other discotics. However, only two of the studied compounds (1a and 4a) are able to form liquid crystalline (lc) mesophases indicating for the other compounds an unfavorable ratio of the core to the periphery size [54].

\section{Intraannular substitution}

The lc phase stability of $1 \mathrm{a}$ within a wide temperature range $\left(63{ }^{\circ} \mathrm{C}\right.$ to $142{ }^{\circ} \mathrm{C}$ ) stimulated the investigation of the derivatives $\mathbf{1 b}-\mathbf{d}$ to elucidate the influence of the intraannular substitution on the phase behavior. In addition, we addressed the question whether an interior change could lead to liquid crystallinity in $\mathbf{2}$.

From the DSC and POM investigations in combination with the chemical structure of the compounds the following observations can be summarized: Although $\mathbf{1 d}$ has an empty lumen it has a similar melting point $\left(62^{\circ} \mathrm{C}\right)$ as $1 \mathrm{a}\left(63^{\circ} \mathrm{C}\right)$, whose cavity crosses an alkyl bridge. Prolonging the intraannular alkyl chain length raises this transition temperature towards $72{ }^{\circ} \mathrm{C}(\mathbf{1 b})$. If a polar template (1c) is used instead, the melting point reaches
89-105 ${ }^{\circ} \mathrm{C}$ (there are most probably two polymorphs, which melt at different temperatures). For comparison, compounds 2a-d melt at $168{ }^{\circ} \mathrm{C}(\mathbf{2 a}), 181{ }^{\circ} \mathrm{C}(\mathbf{2 c})$, and $223{ }^{\circ} \mathrm{C}(\mathbf{2 d})$, respectively (Figure 3, Table 1).

POM investigations indicate that $\mathbf{1 a}$ and $\mathbf{1 d}$ exhibit lc phases. Above the melting point, the sample of 1a exhibits a fan shaped texture under the POM and shear tests indicate a wax-like viscosity of that phase (Figure $4 \mathrm{a}$ ). The melt becomes isotropic when heated above $148{ }^{\circ} \mathrm{C}$ and the lc phase reappears upon cooling below $140{ }^{\circ} \mathrm{C}$. $1 \mathbf{d}$ forms in the temperature interval between $70{ }^{\circ} \mathrm{C}$ and $130{ }^{\circ} \mathrm{C}$ a birefringent lc phase with a characteristic Schlieren-texture (Figure 4b). Here, too, the lc phase reappears upon cooling from the isotropic melt $\left(123^{\circ} \mathrm{C}\right)$.

At lower temperatures, the mesophases of both, 1a and 1d, first solidify and slowly crystallize. The DSC results nicely confirm the POM observations. Corresponding endotherms for the melting and clearing points are visible in the thermograms of $\mathbf{1 a}$ as well as $\mathbf{1 d}$ (Figure $3 \mathrm{~b}$, Table 1). The sample of $\mathbf{1 d}$ seems to melt at $62{ }^{\circ} \mathrm{C}(33 \mathrm{~kJ} / \mathrm{mol})$ into a nematic phase $\left(\mathrm{N}_{1}\right)$ followed by a transition into another nematic phase $\left(\mathrm{N}_{2}\right)$ at $70{ }^{\circ} \mathrm{C}$ $(4.3 \mathrm{~kJ} / \mathrm{mol})$. The $\mathrm{X}$-ray data of both phases are alike (see below). Upon cooling, no crystallization can be observed, either for $1 \mathbf{a}$ or $\mathbf{1 d}$. However, for 1d an exotherm followed by an endotherm is observed upon the second heating indicating crystallization and melting during the experiment. Clear hints on a stable mesophase could be obtained neither for $\mathbf{1 b}$ nor for $\mathbf{1 c}$. From the DSC it seems that also 1c exhibits an 1c phase between $89^{\circ} \mathrm{C}$ and $105^{\circ} \mathrm{C}$. However, from the POM and X-ray data we assume that 1c forms at least two polymorphs which have different melting points. Unfortunately, their formation 

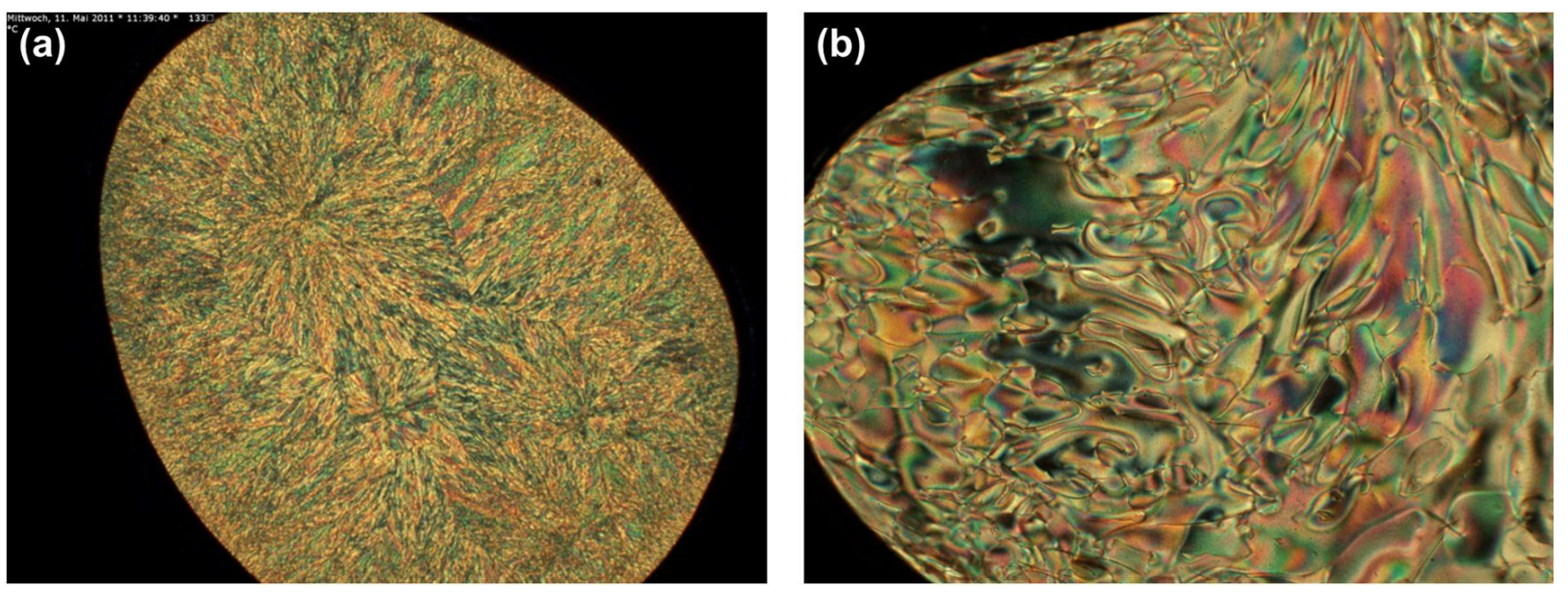

Figure 4: POM images of (a) $1 \mathrm{a}\left(20 \times, 133^{\circ} \mathrm{C}\right.$, upon cooling); (b) $1 \mathbf{d}\left(20 \times, 84^{\circ} \mathrm{C}\right.$, upon heating).

during the heating runs does not occur systematically but randomly.

These observations clearly show that also the intraannular substitution has a considerable influence on the thermal behavior of the macrocycles. The melting point increases in the order $\mathbf{1 d} \approx \mathbf{1 a}<\mathbf{1 b}<\mathbf{1 c}$, showing the contribution of the intraannular template on the thermal behavior of the compounds. While the melting points of $\mathbf{1 a}$ and $\mathbf{1 d}$ are similar, the longer template in 1b increases the melting point slightly and the additional interactions provided by the polar template in $\mathbf{1} \mathbf{c}$ increase the melting point even further. However, the latter two compounds are not liquid crystalline. For $\mathbf{1 b}$ can be assumed that the template is longer than the ring diameter and this leads to a loop in the molecule preventing the formation of an lc phase. For 1c the length of the template seems to be similar to the alkyl template in 1a. However, the tendency of oligoethylene oxides to obtain a helical conformation [55] may fold the arylene-acetylene backbone into a boat conformation which is no longer a discotic mesogen. For the macrocycles $\mathbf{2 a - d}$, the melting points are rather high and clearly above the isotropization temperatures observed for 1a and 1d. The high melting point of $\mathbf{2 d}$ might be explained by an interlocking of the molecules as a result of the empty interior of the rigid backbone [41] A similar observation was also been made earlier on arylene-acetylene macrocycles. The fact that $\mathbf{1 d}$ has a low melting point similar to 1a although the interior is empty, is remarkable and prompted us to investigate $\mathbf{1 a}$ and $\mathbf{1 d}$ in more detail by X-ray diffraction to gain deeper insight into the structure of their liquid crystalline phases.

\section{X-ray diffraction}

A sample of 1d was kept in a glass capillary $(\varnothing 1 \mathrm{~mm})$ in a temperature-controlled heating stage and partially aligned in a magnetic field, another one and that of 1a were surface aligned at the sample - air interface on a glass plate on a temperature controlled heating stage, all on slow cooling $(\sim 0.1 \mathrm{~K} / \mathrm{min})$ from the isotropic liquid. 2D patterns were recorded by an area detector HIStar (Siemens/Bruker) using Ni-filtered $\mathrm{Cu} \mathrm{K \alpha}$ radiation.

The patterns of $\mathbf{1 d}$, the compound without intraannular substitution, show in the isotropic liquid at $160{ }^{\circ} \mathrm{C}$ (Figure 5a) the usual outer diffuse scattering at about $4.6 \AA$ characteristic for the average distance between the molecules along their short axes and between the side chains. In the small angle region there are two diffuse rings. These can be an indication of molecular aggregates which are already formed in the isotropic liquid [38]. The pattern slightly changes on cooling at the transition to the liquid crystalline phase and the sample becomes partially aligned in the magnetic field (Figure 5b and Supporting Information File 1 Figure S1 and Table S1). All reflections remain diffuse. Hence, it is a phase without long-range positional order
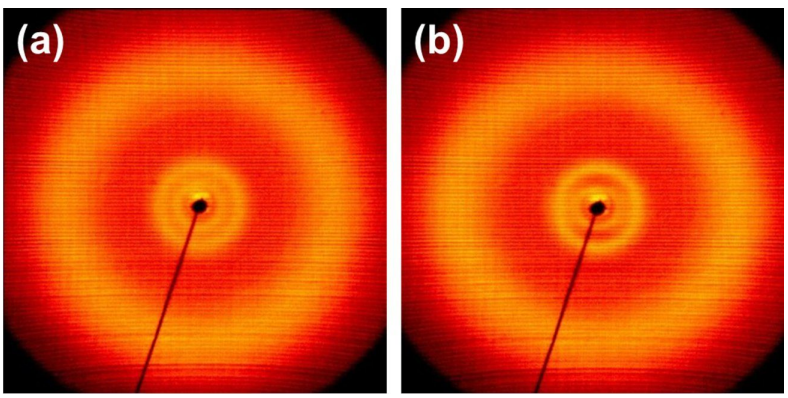

Figure 5: 2D X-ray patterns for $1 \mathrm{~d}$ : (a) isotropic liquid at $160{ }^{\circ} \mathrm{C}$, (b) partially aligned liquid crystalline phase at $120^{\circ} \mathrm{C}$ on cooling. The magnetic field is parallel to the meridian of the pattern. 
and should be a kind of a nematic phase, in agreement with the optical textures. Obviously, similar clusters as in the isotropic phase are observed in the nematic phase. No changes of the $\mathrm{X}$-ray pattern indicating a phase transition could be detected on heating above or on cooling below $70{ }^{\circ} \mathrm{C}$ (see Figure $\mathrm{S} 1$ in Supporting Information File 1) in contrast to those found for the nematic discotic $\left(\mathrm{N}_{\mathrm{D}}\right)$-nematic columnar $\left(\mathrm{N}_{\mathrm{C}}\right)$ transition in liquid crystalline polymers [56] and for the $\mathrm{N}_{D^{-}}$nematic lateral $\left(\mathrm{N}_{\mathrm{L}}\right)$ transition in liquid crystalline charge transfer complexes [57]. Neither magnetic nor surface alignment of the samples was sufficient to get evidence for or against a uniaxial nematic $\left(\mathrm{N}_{\mathrm{u}}\right)$-biaxial nematic $\left(\mathrm{N}_{\mathrm{b}}\right)$ transition which has been extensively discussed in literature (see, e.g., [58]). The texture of the sample in the POM investigations did also not show significant changes like those observed for the $\mathrm{N}-\mathrm{N}_{\mathrm{x}}$ transition of liquid crystalline dimers and bent-core liquid crystals which has recently been identified as a nematic-twist bent nematic $\left(\mathrm{N}_{\mathrm{TB}}\right)$ transition (see, e.g., $[59,60]$ ). Therefore the nature of the phase change indicated by the DSC measurements could not be clarified yet.

The X-ray pattern for the isotropic liquid of 1a (Figure 6a) closely resembles that of $\mathbf{1 d}$, only the intensity ratio for the two inner rings differs. The changes at the phase transitions are more dramatic as in case of $\mathbf{1 d}$ (Figure 6b). Indeed, the outer scattering also shows a ring-like part and one with four maxima, but the latter are found $45^{\circ}$ above and below the equator and the inner scattering splits into Bragg reflections (Figure 6d) which can be indexed on a rectangular two-dimensional lattice (plane group $p 2 g g$, reflections $h 0$ only observed for $h=2 n$ and $0 k$ for $k=2 n$, cp. Figure 6c) with cell parameters $a=28.9 \AA$, $b=52.0 \AA$ at $100{ }^{\circ} \mathrm{C}$ (Supporting Information File 1, Table S2) similar, for instance, to the $2 \mathrm{D}$ symmetry of the columnar lc phases of macrocycles reported in [40].

A plausible packing for the molecules is a stacking of the macrocycles in columns, in which the mean planes of the cycles have a $45^{\circ}$ tilt angle with respect to the columnar axes. The columns in turn are arranged in the 2D lattice described above. Assuming one molecule in the cross section of a column with $\mathrm{C}_{2}$ symmetry, the number of columns and hence of molecules in the cross section of the unit cell in this lattice is 2 . For this packing model a reasonable density of $1.17 \mathrm{~g} / \mathrm{cm}^{3}$ is calculated using an average stacking distance $h=4.6 \AA / \cos 45^{\circ}=6.5 \AA$ of the macrocycles along the columnar axis $\left(\rho_{\text {calc }}=\right.$ $n_{\text {cell }} * M / V_{\text {cell }} / \mathrm{A}$ with a volume of an average $3 \mathrm{D}$ unit cell $V_{\text {cell }}=a * b * h=9768.2 \AA^{3}$ and $\mathrm{A}=$ Avogadro constant). The assumed packing model also allows to understand the columnar phase stability. A MMFF calculation (Spartan '08) of a short column of tilted macrocycles shows a local minimum arrangement with a close contact between the intraannular alkyl chains
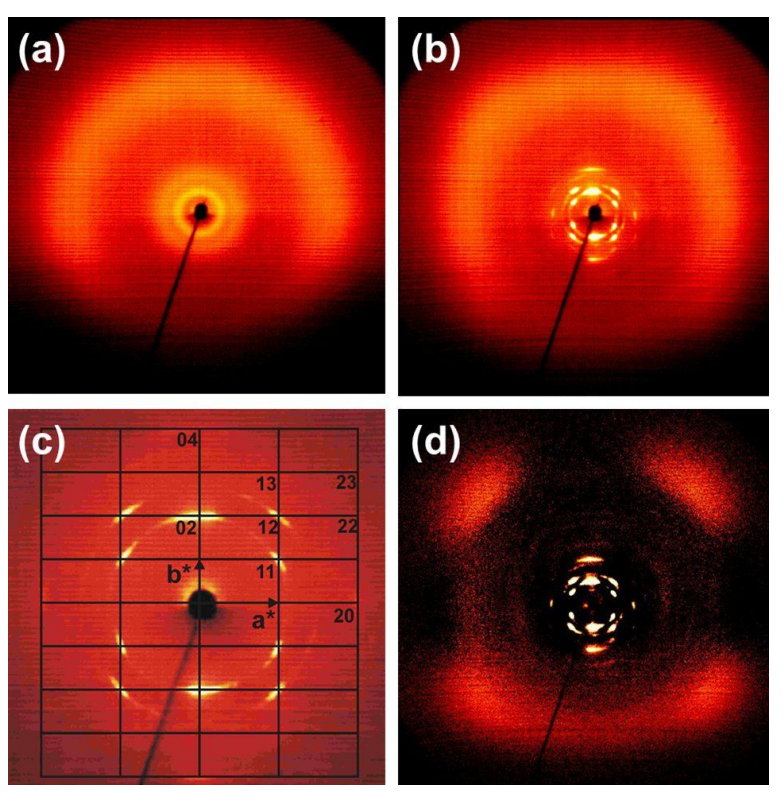

Figure 6: 2D X-ray patterns for 1a: (a) isotropic liquid at $150^{\circ} \mathrm{C}$

(b) columnar mesophase at $100^{\circ} \mathrm{C}$, surface aligned on cooling,

(c) small angle region at $100^{\circ} \mathrm{C}$ with reciprocal axes and indices for the $2 \mathrm{D}$ lattice of the columnar phase, (d) scattering at $150^{\circ} \mathrm{C}$

subtracted from that at $100{ }^{\circ} \mathrm{C}$ to enhance the effect of the anisotropic distribution of the diffuse scattering.

(Figure 7). It might be the additional packing effect of the intraannular alkyl chains which stabilizes the columnar phase. A similar effect (although with polar intraannular ester groups) has been observed previously [40]. However, in that particular case, the analogue non-filled macrocycle is not liquid crystalline. The packing model in Figure 7 also indicates that the longer intraannular alkyl bridge of $\mathbf{1 b}$ prevents a close packing of the rings and leads in this case even to the absence of the lc phase.

\section{Conclusion}

In summary, shape-persistent macrocycles with intraannular bridges were synthesized by oxidative Glaser-coupling of the appropriate acetylenes. The bridges serve during the synthesis as a covalent template. Compounds with branched extraannular side chains exhibit in some cases liquid crystalline phases. Depending on the ring interior, either a nematic (empty interior) or a columnar phase (alkyl template) could be observed, as determined by differential scanning calorimetry, optical microscopy and X-ray scattering. It can be assumed that the additional van der Waals interaction between the stretched intraannular alkyl chains stabilize the packing of the rings on top of each other. When the alkyl bridge is longer than the ring interior or when an oligoether template crosses the ring, no lc behavior is observed. In both cases an induced non-planarity of the macrocycles is assumed. 
(a)

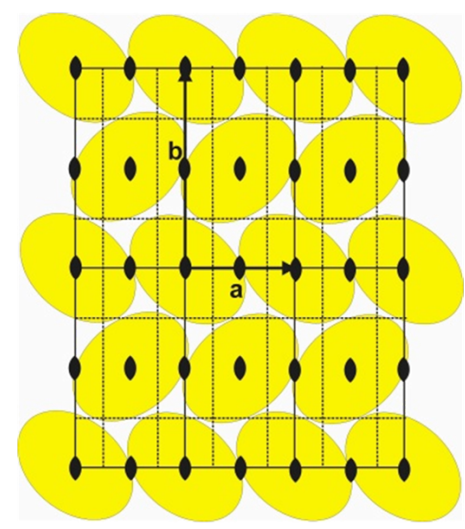

(b)

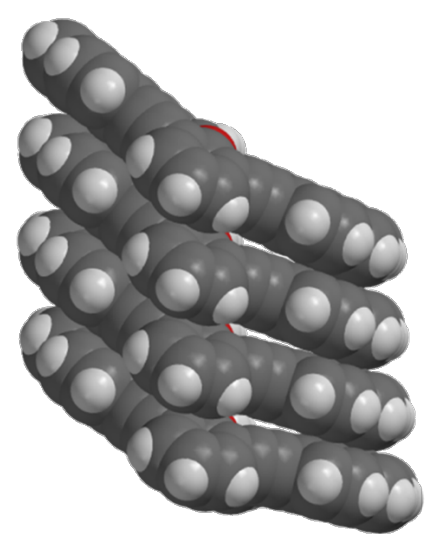

(c)

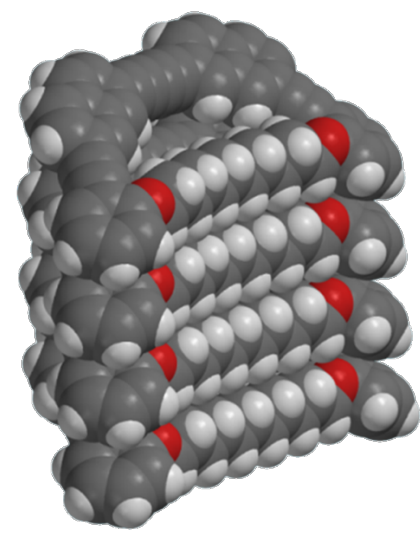

Figure 7: Model of the molecular packing in the columnar mesophase of 1a: (a) 2D packing scheme for the columns in the liquid crystalline phase (plane group p2gg, arbitrary cross section of the columns to fit the symmetry); MMFF calculation (Spartan '08) of a tetramer of the macrocycles; (b) suggested stacking of the macrocycles within one column (side chains omitted for clarity); (c) visualization of the intraannular alkyl chain packing within the columns.

\section{Supporting Information}

\section{Supporting Information File 1}

Complete experimental details, including ${ }^{1} \mathrm{H}$ and ${ }^{13} \mathrm{C}$ NMR spectra.

[http://www.beilstein-journals.org/bjoc/content/ supplementary/1860-5397-10-89-S1.pdf]

\section{Acknowledgments}

Financial support of the collaborative research centre SFB 624 of the Deutsche Forschungsgemeinschaft (DFG) is gratefully acknowledged.

\section{References}

1. Iyoda, M.; Yamakawa, J.; Rahman, M. J. Angew. Chem., Int. Ed. 2011, 50, 10522-10553. doi:10.1002/anie.201006198

2. Avendaño, C.; Müller, E. A. Soft Matter 2011, 7, 1694-1701. doi:10.1039/c0sm00905a

3. Zhang, W.; Moore, J. S. Angew. Chem., Int. Ed. 2006, 45, 4416-4439. doi:10.1002/anie.200503988

4. Höger, S. Chem.-Eur. J. 2004, 10, 1320-1329. doi:10.1002/chem.200305496

5. Grave, C.; Schlüter, A. D. Eur. J. Org. Chem. 2002, 3075-3098. doi:10.1002/1099-0690(200209)2002:18<3075::AID-EJOC3075>3.0.C o;2-3

6. Haley, M.; Pak, J.; Brand, S. Macrocyclic Oligo(phenylacetylenes) and Oligo(phenyldiacetylenes). In Carbon Rich Compounds II: Macrocyclic Oligoacetylenes and Other Linearly Conjugated Systems; de Meijere, A., Ed.; Springer: Berlin/Heidelberg, 1999; Vol. 201, pp 81-130.

7. Tahara, K.; Balandina, T.; Furukawa, S.; De Feyter, S.; Tobe, Y. CrystEngComm 2011, 13, 5551-5558. doi:10.1039/c1ce05336a
8. Chen, T.; Pan, G.-B.; Wettach, H.; Fritzsche, M.; Höger, S.; Wan, L.-J.; Yang, H.-B.; Northrop, B. H.; Stang, P. J. J. Am. Chem. Soc. 2010, 132, 1328-1333. doi:10.1021/ja907220f

9. Mena-Osteritz, E.; Bäuerle, P. Adv. Mater. 2006, 18, 447-451. doi:10.1002/adma.200501575

10. Pan, G.-B.; Cheng, X.-H.; Höger, S.; Freyland, W. J. Am. Chem. Soc. 2006, 128, 4218-4219. doi:10.1021/ja060469f

11. Vollmeyer, J.; Jester, S.-S.; Eberhagen, F.; Prangenberg, T.; Mader, W.; Höger, S. Chem. Commun. 2012, 48, 6547-6549. doi:10.1039/c2cc32804f

12. Wettach, H.; Höger, S.; Chaudhuri, D.; Lupton, J. M.; Liu, F.; Lupton, E. M.; Tretiak, S.; Wang, G.; Li, M.; De Feyter, S.; Fischer, S.; Förster, S. J. Mater. Chem. 2011, 21, 1404-1415. doi:10.1039/c0jm02150d

13. Cantin, K.; Rondeau-Gagné, S.; Néabo, J. R.; Daigle, M.; Morin, J.-F. Org. Biomol. Chem. 2011, 9, 4440-4443. doi:10.1039/c1ob05441d

14. Nakagaki, T.; Harano, A.; Fuchigami, Y.; Tanaka, E.; Kidoaki, S.; Okuda, T.; Iwanaga, T.; Goto, K.; Shinmyozu, T. Angew. Chem., Int. Ed. 2010, 49, 9676-9679. doi:10.1002/anie.201004992

15. Fritzsche, M.; Jester, S.-S.; Höger, S.; Klaus, C.; Dingenouts, N.; Linder, P.; Drechsler, M.; Rosenfeldt, S. Macromolecules 2010, 43, 8379-8388. doi:10.1021/ma1016242

16. Che, Y.; Yang, X.; Zhang, Z.; Zuo, J.; Moore, J. S.; Zang, L. Chem. Commun. 2010, 46, 4127-4129. doi:10.1039/c0cc00823k

17. Balakrishnan, K.; Datar, A.; Zhang, W.; Yang, X.; Naddo, T.; Huang, J.; Zuo, J.; Yen, M.; Moore, J. S.; Zang, L. J. Am. Chem. Soc. 2006, 128, 6576-6577. doi:10.1021/ja0618550

18. Rosselli, S.; Ramminger, A.-D.; Wagner, T.; Silier, B.; Wiegand, S.; Häußler, W.; Lieser, G.; Scheumann, V.; Höger, S. Angew. Chem., Int. Ed. 2001, 40, 3137-3141. doi:10.1002/1521-3773(20010903)40:17<3137::AID-ANIE3137>3.0.CO ;2-\#

19. Höger, S.; Bonrad, K.; Mourran, A.; Beginn, U.; Möller, M. J. Am. Chem. Soc. 2001, 123, 5651-5659. doi:10.1021/ja003990x

20. Moore, J. S. Acc. Chem. Res. 1997, 30, 402-413. doi:10.1021/ar950232g 
21. Tobe, Y.; Utsumi, N.; Kawabata, K.; Naemura, K. Tetrahedron Lett. 1996, 37, 9325-9328. doi:10.1016/S0040-4039(97)82954-1

22. Zhang, J.; Moore, J. S. J. Am. Chem. Soc. 1992, 114, 9701-9702. doi:10.1021/ja00050a083

23. Jin, Y.; Zhang, A.; Huang, Y.; Zhang, W. Chem. Commun. 2010, 46, 8258-8260. doi:10.1039/c0cc02941f

24. Kim, J.-K.; Lee, E.; Lee, M. Macromol. Rapid Commun. 2010, 31 980-985. doi:10.1002/marc.200900879

25. Seo, S. H.; Chang, J. Y.; Tew, G. N. Angew. Chem., Int. Ed. 2006, 45, 7526-7530. doi:10.1002/anie.200600688

26. Xu, Y.; Smith, M. D.; Geer, M. F.; Pellechia, P. J.; Brown, J. C.; Wibowo, A. C.; Shimizu, L. S. J. Am. Chem. Soc. 2010, 132, 5334-5335. doi:10.1021/ja9107066

27. Höger, S.; Enkelmann, V. Angew. Chem., Int. Ed. Engl. 1996, 34 2713-2716. doi:10.1002/anie.199527131

28. Höger, S.; Morrison, D. L.; Enkelmann, V. J. Am. Chem. Soc. 2002, 124, 6734-6736. doi:10.1021/ja017628+

29. Bushby, R. J.; Kawata, K. Liq. Cryst. 2011, 38, 1415-1426. doi:10.1080/02678292.2011.603262

30. Bisoyi, H. K.; Kumar, S. Chem. Soc. Rev. 2010, 39, 264-285. doi:10.1039/b901792p

31. Shimura, H.; Yoshio, M.; Kato, T. Org. Biomol. Chem. 2009, 7, 3205-3207. doi:10.1039/b908669b

32. Seo, S. H.; Jones, T. V.; Seyler, H.; Peters, J. O.; Kim, T. H.; Chang, J. Y.; Tew, G. N. J. Am. Chem. Soc. 2006, 128, 9264-9265. doi:10.1021/ja060354b

33. Kumar, S. Chem. Soc. Rev. 2006, 35, 83-109. doi:10.1039/b506619k

34. Bushby, R. J.; Lozman, O. R. Curr. Opin. Colloid Interface Sci. 2002, 7, 343-354. doi:10.1016/S1359-0294(02)00085-7

35. Zhang, J.; Moore, J. S. J. Am. Chem. Soc. 1994, 116, 2655-2656. doi:10.1021/ja00085a070

36. Fritzsche, M.; Bohle, A.; Dudenko, D.; Baumeister, U.; Sebastiani, D.; Richardt, G.; Spiess, H. W.; Hansen, M. R.; Höger, S.

Angew. Chem., Int. Ed. 2011, 50, 3030-3033. doi:10.1002/anie.201007437

37. Naddo, T.; Che, Y.; Zhang, W.; Balakrishnan, K.; Yang, X.; Yen, M.; Zhao, J.; Moore, J. S.; Zang, L. J. Am. Chem. Soc. 2007, 129, 6978-6979. doi:10.1021/ja070747q

38. Laschat, S.; Baro, A.; Steinke, N.; Giesselmann, F.; Hägele, C.; Scalia, G.; Judele, R.; Kapatsina, E.; Sauer, S.; Schreivogel, A.; Tosoni, M. Angew. Chem., Int. Ed. 2007, 46, 4832-4887. doi:10.1002/anie.200604203

39. Mindyuk, O. Y.; Stetzer, M. R.; Heiney, P. A.; Nelson, J. C.; Moore, J. S. Adv. Mater. 1998, 10, 1363-1366. doi:10.1002/(SICI)1521-4095(199811)10:16<1363::AID-ADMA1363>3. $0 . \mathrm{CO} ; 2-\mathrm{V}$

40. Fischer, M.; Lieser, G.; Rapp, A.; Schnell, I.; Mamdouh, W.; De Feyter, S.; De Schryver, F. C.; Höger, S. J. Am. Chem. Soc. 2004, 126, 214-222. doi:10.1021/ja038484x

41. Höger, S.; Cheng, X. H.; Ramminger, A.-D.; Enkelmann, V.; Rapp, A.; Mondeshki, M.; Schnell, I. Angew. Chem., Int. Ed. 2005, 44, 2801-2805. doi:10.1002/anie.200462319

42. Höger, S.; Enkelmann, V.; Bonrad, K.; Tschierske, C. Angew. Chem., Int. Ed. 2000, 39, 2267-2270. doi:10.1002/1521-3773(20000703)39:13<2267::AID-ANIE2267>3.0.CO ;2-7

43. Li, Q.; Huang, R.; Xiong, S.; Xie, X. Liq. Cryst. 2012, 39, 249-258. doi:10.1080/02678292.2011.636843

44. Höger, S.; Weber, J.; Leppert, A.; Enkelmann, V. Beilstein J. Org. Chem. 2008, 4, No. 1. doi:10.1186/1860-5397-4-1
45. Ziegler, A.; Mamdouh, W.; Ver Heyen, A.; Surin, M.; Uji-i, H.; Abdel-Mottaleb, M. M. S.; De Schryver, F. C.; De Feyter, S.; Lazzaroni, R.; Höger, S. Chem. Mater. 2005, 17, 5670-5683. doi:10.1021/cm051386I

46. Collings, P. J.; Hird, M. Introduction to Liquid Crystals: Chemistry and Physics; Taylor \& Francis: London, 1997. doi:10.4324/9780203211199

47. Collard, D. M.; Lillya, C. P. J. Am. Chem. Soc. 1991, 113, 8577-8583. doi:10.1021/ja00023a001

48. Höger, S. J. Polym. Sci., Part A: Polym. Chem. 1999, 37, 2685-2698. doi:10.1002/(SICI)1099-0518(19990801)37:15<2685::AID-POLA1>3.0. CO;2-S

49. Rucareanu, S.; Schuwey, A.; Gossauer, A. J. Am. Chem. Soc. 2006, 128, 3396-3413. doi:10.1021/ja057117d

50. McCallien, D. W. J.; Sanders, J. K. M. J. Am. Chem. Soc. 1995, 117, 6611-6612. doi:10.1021/ja00129a033

51. Höger, S.; Meckenstock, A.-D. Chem.-Eur. J. 1999, 5, 1686-1691. doi:10.1002/(SICI)1521-3765(19990604)5:6<1686::AID-CHEM1686>3 $0 . \mathrm{CO} ; 2-0$

52. Pisula, W.; Feng, X.; Müllen, K. Adv. Mater. 2010, 22, 3634-3649. doi:10.1002/adma.201000585

53. Kumar, S. Chemistry of Discotic Liquid Crystals: From Monomers to Polymers; CRC Press: Boca Raton, 2010. doi:10.1201/b10457

54. Kohne, B.; Praefcke, K. Chem.-Ztg. 1985, 109, 121-127.

55. Gnanou, Y.; Fontanille, M. Organic and Physical Chemistry of Polymers; John Wiley \& Sons: Hoboken, New Jersey, 2008; Vol. 1. doi:10.1002/9780470238127

56. Kouwer, P. H. J.; Jager, W. F.; Mijs, W. J.; Picken, S. J. Macromolecules 2000, 33, 4336-4342. doi:10.1021/ma991808a

57. Kouwer, P. H. J.; Jager, W. F.; Mijs, W. J.; Picken, S. J. Macromolecules 2001, 34, 7582-7584. doi:10.1021/ma011007j

58. Tschierske, C.; Photinos, D. J. J. Mater. Chem. 2010, 20, 4263-4294. doi:10.1039/b924810b

59. Cestari, M.; Diez-Berart, S.; Dunmur, D. A.; Ferrarini, A.; de la Fuente, M. R.; Jackson, D. J. B.; Lopez, D. O.; Luckhurst, G. R.; Perez-Jubindo, M. A.; Richardson, R. M.; Salud, J.; Timimi, B. A.; Zimmermann, H. Phys. Rev. E 2011, 84, 031704. doi:10.1103/PhysRevE.84.031704

60. Chen, D.; Nakata, M.; Shao, R.; Tuchband, M. R.; Shuai, M.; Baumeister, U.; Weissflog, W.; Walba, D. M.; Glaser, M. A.; MacLennan, J. E.; Clark, N. A. Phys. Rev. E 2014, 89, 022506. doi:10.1103/PhysRevE.89.022506 


\section{License and Terms}

This is an Open Access article under the terms of the Creative Commons Attribution License

(http://creativecommons.org/licenses/by/2.0), which permits unrestricted use, distribution, and reproduction in any medium, provided the original work is properly cited.

The license is subject to the Beilstein Journal of Organic Chemistry terms and conditions:

(http://www.beilstein-journals.org/bjoc)

The definitive version of this article is the electronic one which can be found at:

doi:10.3762/bjoc. 10.89 